\title{
DIMENSÕES DA CONFIANÇA NOS CONTRATOS EMPRESARIAIS: O PAPEL DO DIREITO NA TUTELA DAS RELAÇÕES CONTRATUAIS
}

\section{DIMENSIONS OF TRUST: THE ROLE OF LAW GOVERNING \\ CONTRACT LAW}

Recebimento em 09/09/2020

Aceito em 24/09/2020

\author{
Daniel Fideles Steinberg ${ }^{1}$ \\ Tarcísio de Souza Neto ${ }^{2}$
}

\section{RESUMO}

Confiança é um recurso indispensável para sustentar relações contratuais.A hipótese do presente artigo é que o direito é uma tecnologia fundamental para tutelar a confiança empresarial, que isso já ocorre e que pode, e é interessante, ser maximizado. As perguntas de pesquisa do presente artigo são: (i) qual a relevância de tutelar a confiança nos contratos empresariais? e (ii) como por quais mecanismos jurídicos - ela pode ser tutelada? A metodologia de pesquisa é eminentemente doutrinária, buscando guiar o leitor por meio de posições teóricas defendidas por autores de direito contratual e da nova economia institucional. Entende-se que a sedimentação da confiança no tecido social depende de aportes jurídicos, tanto como critério de decidibilidade, como reguladora do ambiente institucional.

Palavras-chave: Contratos empresariais. Confiança. Tutela jurídica. Nova Economia Institucional. Custos de transação.

\section{ABSTRACT}

Trust is an indispensable resource for sustaining contractual bonds. The hypothesis of the present article is that law is a fundamental technology to protect corporate trust, that this already occurs and can be maximized. The research questions in this article are: (i) What is the relevance of safeguarding trust in business contracts? and (ii) how - by what legal mechanisms - can it be protected? The research methodology is theoretical, seeking to guide the reader through the positions defended by authors of contract law and the new institutional economics. It is understood that the sedimentation of trust depends on legal contributions, as a criterion of decidability, as a regulator of the institutional environment.

Keywords: Contracts.Trust.Legal enforcement.New Institutional Economics.Transaction costs.

\footnotetext{
${ }^{1}$ Doutorando e mestre no Departamento de Filosofia e Teoria do Direito da Faculdade de Direito de São Paulo (USP). Advogado em São Paulo.

${ }^{2}$ Mestrando em Direito pela Universidade de São Paulo (USP) - Departamento de Direito Comercial, especialista em direito contratual e graduado pela Faculdade de Direito do Recife, vinculada à Universidade Federal de Pernambuco, advogado.
} 


\section{INTRODUÇÃO}

A confiança tem um papel fundamental na estabilização das expectativas sociais, econômicas e normativas. No limite, é possível afirmar que confiança está intimamente associada ao risco: como a confiança é somente um mecanismo de redução da complexidade social, ela permite oferecer apenas certo nível de segurança presente para orientações futuras. Engajar-se em confiança, portanto, importa em assumir certos riscos (GIDDENS, 1991, p. 40).

A premissa deste artigo é que a confiança é necessariamente uma aposta, feita no presente, orientada para o futuro, a partir de entendimentos passados. Ou seja, uma aposta cujo objetivo é reduzir a complexidade (social, econômica e/ou jurídica), mas que, paradoxalmente, pode acabar aumentando o leque de possibilidades à disposição do agente social (LUHMANN, 2005). O objeto do presente artigo é tratar da complexidade econômica encetada nas operações contratuais e seu entrelace com o tratamento jurídico dos contratos.

Duas perguntas nortearão o presente artigo: (i) qual a relevância de tutelar a confiança nos contratos empresariais? e (ii) como - por quais mecanismos jurídicos - ela pode ser tutelada? A hipótese é que o direito é um instrumento importante para assegurar a confiança nas relações empresariais: partindo de premissas da nova economia institucional ("NEI"), entende-se que a sedimentação da confiança no tecido social depende de aportes jurídicos. Deste modo, a confiança não dependeria somente de padrões de comportamento usualmente aceitos em determinado mercado, ligado aos usos e costumes, mas também poderia ser acrescida de elementos jurídicos para assegurar, por exemplo, a diminuição dos custos de transação. ${ }^{3}{ }^{4}$

Parte-se da premissa que o fenômeno dos contratos empresariais ocorre em três campos da vida social: no campo econômico, no mercado, e no campo jurídico. Assim, ele opera simultaneamente nos seguintes contextos: (i) é uma transação econômica; (ii) é um ato produtivo; e (iii) modifica a situação legal. Ou seja, é ao mesmo tempo transação, produção e obrigação(TEUBNER, 2006).

\section{CONTRATO E CONFIANÇA: COMO A RELAÇÃO SE ESTABELECE?}

\footnotetext{
${ }^{3}$ Parte-se da premissa neoclássica que as trocas econômicas podem se aproximar a eficiência de Pareto quando e se estabelecidas em cenário de custos de transação igual a zero.

${ }^{4}$ Assim, se a confiança tende a estabilizar as expectativas sociais e econômicas, conforme já afirmado, a sua proteção, pelo ordenamento jurídico, resulta em assegurar as legítimas expectativas.
} 
$\mathrm{Na}$ esfera jurídica, o contrato funciona produzindo efeitos legais específicos, desde que atenda aos padrões normatizados que os determina. A regulação ocorre nos três planos do negócio jurídico: existência, validade e eficácia. O contrato como fenômeno econômico poderá ou não existir para o direito, ser ou não válido e ter seus efeitos esperados exigíveis, e todos esses níveis de regulação causarão uma resposta no mundo econômico, um incentivo ou desincentivo. Isto é, mesmo os requisitos de sua existência para o mundo jurídico - ou as situações em que o contrato para ele não existirá - influenciam no que será o fenômeno daquele contrato nos demais campos.

Enquanto o sistema econômico se movimenta por uma lógica de custo-benefício, de incentivos, o sistema jurídico possui lógica própria de comando e controle(FERRAZ JÚNIOR, 2019, p. 277).Então mesmo a exclusão feita pelo sistema jurídico, será interpretada pelo sistema econômico sob a ótica de incentivos. Quando o sistema jurídico opta por não dar o efeito jurídico esperado para um determinado contrato, até mesmo não lhe considerar um contrato, cria um incentivo específico no sistema econômico, de que essa negociação que foi feita não será abarcada por aquele regramento, o que pode importar em um custo menor ou maior para a relação. Isto acontece com toda resposta dada pelo sistema jurídico ao fenômeno do contrato.

Sendo assim, quando se analisa a relevância ou não da regulação da confiança nos contratos empresariais, e de que forma ela poderia ser tutelada, parece salutar que seja entendido o contrato no campo econômico, e como são recebidos os incentivos vindos do campo jurídico, e em que ambiente eles são aplicados. Compreender os efeitos da regulação é fundamental para que esta consiga atender ao fim para o qual foi pensada.

Em RegulatingContracts, Collins afirma que o risco da frustração comercial nunca pode ser completamente eliminado. Para o autor, confiança e sanção são variáveis relevantes na análise do risco contratual. A confiança decorre da fé (faith) de que a contraparte comercial irá adimplir a respectiva obrigação; a sanção, por sua vez, é uma possibilidade de punição em razão do inadimplemento, podendo acarretar perdas econômicas. A tese de Collins é que apesar da confiança ser mais difícil de alcançar e manter, ela é mais eficaz do que a sanção para sustentar uma relação comercial(2004, p. 99).

Collins anota que a confiança não deriva de padrões morais, mas sim da relação pessoal entre os parceiros comerciais. Nas suas palavras: "Confiança envolve acreditar no conhecimento que se tem sobre a outra pessoa. Esse conhecimento deriva desde a intimidade adquirida por transações passadas e interação social ou por meio de atributos da identidade da pessoa"(2004, p. 99). 
Assim, confiança e sanção criam as condições necessárias para a formação dos mercados, de modo que só há relação mercantil se o potencial de ganho exceder a probabilidade de perda em razão da frustração. Enquanto a variável confiança aloca-se nos dois lados da equação (benefício e frustração), a sanção inibe apenas a frustração, não havendo, contudo, incentivos positivos(COLLINS, 2004, p. 102).Em resumo, a confiança e sanções não jurídicas diminuem os custos de transação - assim, para Collins, a existência de sanção jurídica: (i) raramente é um fator determinante para encorajar as partes a entrarem em uma relação contratual; e (ii) não é o principal meio em que as partes se protegem do risco de inadimplemento (2004, p. 108).Além disso, sanções não-jurídicas sãouma forma de guiar o auto-interesse, tornando o comportamento das partes mais previsível (2004, p. 130).

De acordo com Collins, o direito é periférico para sustentar as relações contratuais, sendo, em alguma medida, irrelevante (2004, p. 104). Nesse sentido, a tutela da confiança ocorreria de forma orgânica nas relações comerciais, com base em critérios pessoais entre os sujeitos da transação. De qualquer forma, trata-se de um entendimento orgânico da confiança, como um valor presente no tecido social e que nortearia, consequentemente, as relações comerciais.

Mercados poderiamflorescer, portanto, com confiança sem a existência de sanção (jurídica). Confiança é construída por meio de interação social, normalmente em meio a grupos étnicos ou em território limitado e específico(BERNSTEIN, 1992). São ambientes em que, diante da necessidade de mecanismos extras para que as questões econômicas possam funcionar, superando interesses individuais por coletivos, surge a solução da moral do grupo, e o aprimoramento da confiança (GREENE, 2013). Para Zucker, a confiança pode ser aprofundada ao criar padrões de interações sociais, por meio de códigos de conduta, associações comerciais e acordos comerciais (ZUCKER, 1986).Nesses casos, defendem os autores, as sanções nãojurídicas, como areputacional e a creditícia, são geralmente mais efetivas do que as jurídicas.

Judith Martins-Costa ensina que os contratos provocam uma eficácia geradora de vínculo jurídico obrigacional entre as partes contratantes, ligadas por uma expectativa de confiança para manter o que foi pactuado (2011, p. 55). Naturalmente, tal vínculo estará permeado por sanções: Collins sustenta que efeitos econômicos (não jurídicos) são mais eficazes do que os jurídicos para sustentar respectiva relação contratual, favorecendo a performance diligente da contraparte em razão do risco do inadimplemento.

Para ser mais específico, Collins afirma que em algumas situações as partes preferem não executar o contrato, mesmo existindo cláusula nesse sentido (2004, p. 123).É nesse aspecto que a teoria apresentada por Collins parece ser descolada das práticas comerciais. Isto porque,em 
especial tratando-se de partes sofisticadas ${ }^{5}$, haverá uma alocação de riscos bastante específica pelas partes, mas a possibilidade de conflito sempre estará presente. É possível conceber, como faz Collins, a confiança como valor imanente aos mercados, sustentada pela esfera econômica? Seria a auto-regulação contratual método eficiente, como acredita Collins? É sustentável o regime híbrido de direito contratual na construção de mercado? Em muitos aspectos, Collins parece desprezar duas questões: (i) as regras de direito contratual também tutelam a confiança empresarial; e (ii) em certas situações contratuais, especialmente envolvendo objetos contratuais complexos, engajar-se em confiança pode ser uma atitude comercialmente vaga e/ou inútil.

Do ponto de vista teórico, parece ser essencial analisar os contratos sob a ótica da Nova Economia Institucional (WILLIAMSON, 1998), especialmente a economia de custos de transação. Isto porque, como descreve Williamson, a Economia dos Custos de Transação (“ECT") tem em si uma abordagem micro analítica interdisciplinar do que desafia o direito, a economia e as organizações. ${ }^{6}$ Ao contrário das concepções econômicos anteriores, de que o capitalismo era explicado por interesse de classe, tecnologia, monopólio etc. A abordagem dos custos de transação defende que o propósito principal disto tudo é reduzir os custos de transação (COASE, 1993), isto é, custos não diretamente ligados à produção, mas que surgem à medida que os agentes se relacionam entre si e problemas de coordenação de suas ações emergem (FARINA, 1997, p. 55), sendo a transação a unidade básica de análise (COMMONS, 1934).

Analisando a transação, observa-se inicialmente que, segundo Karl Llewellyn, a importância do contrato é promover a estrutura (no original,canvas ouframework)(LLEWELLYN, 1931).Essa visão se aproxima de Collins, inclusive no que diz respeito à possível irrelevância do direito e da importância relacional. A partir desta concepção, contrato seria uma moldura institucional geradora de incentivos econômicos para as partes, em que a confiança poderia ser um dos fatores para sustentá-la.

Williamson deixa claro que o ambiente da transação conforme estuda a economia dos custos de transação tem algumas características fixas (1998,p. 10; 44-45). Fundamentalmente, é um ambiente em que há a racionalidade do agente econômico, que fará as estipulações e projeções prevendo um comportamento futuro. No entanto, é impossível que esta racionalidade seja plena. A complexidade do mundo é inafastável. É impossível que todas as possibilidades de futuro sejam previstas pelo agente econômico, ainda que este seja racional.

\footnotetext{
${ }^{5}$ Expressão usada no sentido de qualificar as partes que tiveram oportunidade e meios para se dedicar à elaboração daquela relação, e de fato fizeram, dispondo de recursos avançados, e profissionais especializados para construir o contrato como pretendido.
} 
Além da impossibilidade racional de se saber tudo, o agente está inserido em um contexto que delimita a sua racionalidade. Daí o nome dado de boundedrationality, traduzido como racionalidade limitada. $\mathrm{O}$ termo se justifica porque a racionalidade existente está contida em um contexto específico daquele agente, que só pode lidar com a informação que tem acesso, recebida com suas limitações cognitivas, e com um tempo finito para conclusão. Sempre é possível buscar mais conhecimento para que se consiga aumentar a racionalidade, isto é, para que sejam levados em conta por aquele agente mais exemplos e o futuro possa ser antecipado mais precisamente. Contudo, isto sempre será um custo. Tanto de tempo, como de custo efetivo. Então, haverá sempre o ponto em que o aumento do custo para que se amplie a racionalidade retirará completamentea vantagem em se fazer o negócio. Este é o limite econômico da racionalidade do agente.

Outro aspecto indispensável é o do oportunismo. O indivíduo terá sempre um comportamento oportunista - interesse pessoal com astúcia. É possível que o comportamento oportunista de um indivíduo não implica necessariamente no prejuízo do outro. Mas pode implicar. Em muitas ocasiões, é mais oportuno ao indivíduo se comportar de forma que beneficie o outro agente porque a continuidade do relacionamento lhe trará mais benefícios do que uma vantagem maior momentânea, especialmente em situações de "jogadas repetidas".

Não bastasse isto, toda negociação tem seu custo. Seja o custo de advogado, seja o custo de tempo, de negociação das cláusulas, de deixar de se estar fazendo outra negociação (custo de oportunidade). Tudo isto são custos de transação, que determinam se é melhor buscar a solução pretendida no mercado ou internalizar ao custo de gerência. A analogia mais didática parece ser a dos custos de transação com a fricção. Pensar a economia incluindo os custos de transação é o equivalente de colocar no cálculo da física mecânica o atrito existente. É a ciência buscando retratar ao máximo a realidade, fazendo seus modelos saírem do universo do laboratório.

Sendo estas as características fixas do ambiente de transação, é possível identificar uma balança, em que o esforço - os custos de transação - para se ampliar os limites da racionalidade, a fim de se defender do oportunismo alheio, não pode ultrapassar o custo total para que a transação faça sentido. Diversas medidas podem ser tomadas pelo indivíduo para aumentar a previsibilidade, sendo que cada medida desta será um custo.

Por outro lado, quanto maior a confiança entre os agentes de que não haverá um comportamento oportunista da contraparte, menor será o custo empreendido para a transação. Em outras palavras, confiança pode ser posta no mesmo campo da previsibilidade, ampliador da força da racionalidade, uma vez que reduzirá a complexidade inerente do futuro, enquanto o oportunismo está no mesmo polo que o risco, ampliando a complexidade do futuro. Não por 
acaso que é de saber comum que operações mais arriscadas impõem retornos maiores para que aconteçam. Quando se reduz a previsibilidade, quando se aumenta o risco de que o projetado não ocorra, maior deve ser a expectativa de lucro para que incentive o indivíduo a realizar a transação.

Em contrapartida, a confiança funciona como um redutor de risco, que fomenta a realização de transações, facilitando a sua ocorrência. Quando se há maior previsibilidade de qual será o comportamento da contraparte, menor precisará ser o investimento em "aumentar a racionalidade", em prever o futuro, e em evitar o comportamento oportunista. Se menor é o custo para se realizar aquela transação, mais fácil de fazê-la, por mais indivíduos, e em maior volume. Fernando Araújo traduz isso em sua zona de negociação. Isto é, se cada parte tem seus reservations points para negociar, e a zona de negociação é a faixa de interseção entre os reservation points - ou a área em que ambas as partes estariam dispostas a negociar - o aumento da confiança de cada parte arrefece o reservation point, aumentando a zona em que ambas as partes fariam o negócio, ou zona de negociação(ARAÚJO, 2007, p. 51-54). Repetindo a mesma conclusão por uma análise diversa, trata-se de mais confiança promovendo facilidade para a ocorrência da transação.

Contratos típicos se prestam justamente a isso. Há um entendimento social consolidado de expectativas em uma transação empresarial. Esse entendimento passa a ser positivado em um contrato típico. Isto reduz o custo de transação. Não há necessidade em se gastar tempo negociando se as partes aceitarem o que já foi positivado, e há a previsibilidade de se esperar um comportamento típico também pelo adjudicador. Aumento de previsibilidade, aumento de confiança, diminuição de risco, mais fácil de se fazer a transação.

No entanto, a mesma complexidade que impede a racionalidade completa do agente econômico, também funciona como limite ao legislador. Não é possível que todas as possibilidades do comércio sejam traduzidas em contratos típicos. Contudo, é possível que a confiança seja tutelada e se diminua o risco, funcionando também como um catalisador de transações.

O aumento da confiança pode ser traduzido como um redutor de custo de transação. Reduzir custos de transação é reduzir o preço, especialmente para o consumidor final. Também por isso, há uma correlação efetiva entre desenvolvimento de uma nação e o nível de confiança(PEYREFITTE, 1997).

Para isso, o direito pode e deve ser usado como instrumento para se aumentar a confiança. Parece claro que as relações comerciais dependem de um conteúdo mínimo de confiança, que pode ser aportado pelo direito, em especial nas relações entre desconhecidos (aí também 
incluídos os que desconhecem a reputação do outro)(ARAÚJO, 2007, p. 50). Esse aporte dado pelo direito, seja no extremo de desconhecidos, ou mesmo para os contratantes habituais, terá um papel relevante para o aumento das transações e o desenvolvimento da sociedade.

\section{COMO? ALGUNS MEIOS DE O DIREITO CIVIL BRASILEIRO TUTELAR A CONFIANÇA}

É na utilização do direito como instrumento de aumento da confiança, que a NEI vem a divergir profundamente de Collins. Ainda que se entenda que o direito não é necessário para a existência do mercado, parece-nos que ele serve claramente para facilitar o ambiente de trocas. Quando se decide positivar uma proibição de um comportamento contraditório, por exemplo, se está, claramente, buscando vedar o comportamento oportunista.

O contrato, que é considerado uma estrutura de governança pela NEI, está limitado pelo ambiente institucional. O direito é um dos componentes deste ambiente institucional, que pode ser pensado como as regras do jogo. Aqui "regras" não se limita a dispositivos legais, mas tudo o que regula o agente. A operação e a eficiência de um sistema econômico estão limitadas às instituições, sendo certo que um melhor ambiente institucional propicia um maior desenvolvimento(NORTH, 2018).

O direito quando pensado por essa lógica de instituição não está limitado às regras em abstrato, mas como de fato o sistema jurídico funciona e é aplicado. Isto é, a repressão de fato imposto ao comportamento oportunista será muito mais importante do que as regras que o proíbam, ainda que prevejam uma sanção muito mais severa. O efetivo preço colocado pelo sistema jurídico à quebra do contrato é o que molda a transação, a efetiva possibilidade de ser responsabilizado e em que grau.

O próprio Collins parece aceitar que a adjudicação do direito contratual por algum órgão institucionalizado favorece a irradiação da confiança para as transações comerciais subsequentes(2004, p. 124-25). Isto porque, o raciocínio jurídico, como ato de império, filtra informações econômicas de forma seletiva, que por sua vez, são comunicadas aos outros sistemas sociais. O direito decide, afirma Ferraz Júnior (rightorwrong)(2019, p. 65). O efeito mais forte do sistema legal é provocar certo comportamento social. Vale dizer, a adjudicação das normas jurídicas cria uma camada de confiança social que favorece a aceitação de outras sanções pelos agentes econômicos. A decisão judicial é uma declaração pública que é tida pela comunidade como confiável, fato, verdade. O direito, portanto, cria e garante a confiança. 
Trazendo um exemplo figurativo, é possível imaginar como seriam clássicos jogos de futebol se à época existisse o árbitro de vídeo "VAR" revendo os lances cruciais. A regra de jogador de linha não poder colocar a mão na bola existe desde que o futebol foi inventado. No entanto, a revisão com a ajuda de árbitros de vídeo é bem recente. Hoje, em jogos de copa do mundo, todos os lances de gol são revistos. Neste cenário, dificilmente um jogador teria o comportamento oportunista de colocar propositadamente a mão na bola para fazer o gol, sabendo que a jogada seria revista por árbitros com acesso a diversas gravações por câmeras que captam por todos os ângulos do gramado. Mesmo que o juiz não visse a mão, a jogada seria revista e quase certamente o gol seria anulado e o jogador punido. Com esta tecnologia e sua aplicação, dificilmente o famoso gol de mão de Maradona teria existido.

Neste exemplo, entendemos que a regra de proibição de colocar a mão na bola é a regra em abstrato, mas que o direito como instituição não se resume a ela, mas, principalmente, à punição ao jogador que cometer a falta. O VAR aumenta a possibilidade do comportamento tido como esperado pela sociedade - não colocar a mão na boa - seja incentivado, ao garantir a repressão do comportamento divergente. Reduz-se o comportamento oportunista. Menor a possibilidade de um time se sentir prejudicado pelo comportamento oportunista da outra parte, e que isso venha a prejudicar a ocorrência de novos jogos - ainda que este último ponto seja muito difícil de ocorrer no exemplo citado.

O direito contratual, portanto, para além dos incentivos econômicos criados pelas partes, também tutela a confiança empresarial. Deste modo, a elaboração de contratos formais não é ato meramente simbólico como afirma Collins (2004, p. 135), mas decorrente da existência de variáveis socioeconômicas, como o oportunismo e racionalidade limitada dos agentes. Para Araújo, por exemplo, o alicerce jurídico da confiança cria uma segurança para que as pessoas acreditem nas promessas ou tenham clareza jurídica sobre as obrigações das partes vis a vis o respectivo inadimplemento (ARAÚJO, 2007, p. 19).

Basta lembrar que o processo obrigacional está intimamente ligado ao dinamismo comercial contemporâneo, de modo que nas inúmeras situações de inadimplemento contratual sem modificação da base objetiva do negócio jurídico o aumento nos custos de transação será drasticamente elevado, já que as partes tenderão a adotar mais garantias e outros deveres nas relações contratuais subsequentes. A despeito de uma análise sob a ótica do inadimplemento eficiente, é certo que o objetivo das partes contratantes será sempre o cumprimento dos termos contratuais com maior previsibilidade possível(REBOUÇAS, 2017, p. 160). 
Fato é que o sistema jurídico protege a confiança legítima. É exatamente por meio do papel de garantidor da segurança e confiabilidade das relações sociais, que o ordenamento jurídico cumpre seu papel de assegurar a própria autoconfiança do ordenamento jurídico.

O direito quando chamado a pensar o como, nunca pode se afastar do seu porquê. Se a proteção da confiança é valor que permite a realização de mais transações, e isso é buscado pela sociedade, então o como da tutela deve se firmar sobre essas premissas. Não por acaso, nas lições de Da Frada e Portugal, alguns contratos envolvem grau de complexidade mais elevado, justificando nível de confiança mais intensa. Para os autores,

\begin{abstract}
"[...] o reconhecimento de que existem contratos que envolvem uma confiança mais intensa do que aquela que se deposita ordinariamente no plano geral e indiferenciado do tráfico contratual (a seguir logo a expressão germânica 'gesteigertesVertrauensverhältnis') pode justificar um tratamento diferenciado [da confiança] por parte da ordem jurídica. [...] A confiança (a fides) representa no fundo a forma de superação do desnível que uma situação jurídica apresenta devido à incongruência entre o meio jurídico empregue e o fim que se almeja alcançar." (destacamos) (DA FRADA, 2007, p. 544-54)
\end{abstract}

Para tanto, o direito também pode ser ajudado pelas dimensões das transações, conforme estudadas pela ECT. Estas dimensões podem servir para classificar as transações, e com isso determinar a tutela jurídica. A ECT enumera como dimensões: (i) a Incerteza; (ii) a assimetria de informações; (iii) os ativos específicos; e (iv) a repetição. Maior assimetria pode significar uma vulnerabilidade que mereça ser protegida pelo direito. A presença de ativos específicos pode demonstrar a dependência de um dos agentes àquela transação, por ter realizado investimentos irrecuperáveis (sunkcosts), que lhe fazem se submeter ao comportamento oportunista do outro agente, e pode motivar uma atuação diferente do adjudicador. A repetição pode indicar a criação de uma não expectativa de comportamento diverso, modificando o contrato para o direito. Por isso, a observação das transações sob a ótica dessas dimensões é de grande valia para o direito, e o permitirá atuar tutelando a confiança com mais eficiência.

Para que seja efetiva a tutela, não pode se limitar a proteger os direitos fundamentais de liberdade e autonomia, servindo apenas a prevenir quebras semelhantes no futuro ou colocar valor nelas. A interpretação da quebra e do que seria o comportamento oportunista que deve ser afastado pode e deve, ser facilitada com a ajuda da economia aclarandoo que ocorre na transação, pelo lado econômico.

Se há valor no direito proteger a confiança, expandindo as transações;se há uma transação em que o comportamento oportunista de uma parte a faz se aproveitar de investimentos específicos de outrem;e ainda, se há, na realização desses investimentos um valor social que 
supera a relação das partes, por ajudar a reduzir os custos de transação e facilitar a realização das transações,então, o direito deverá proteger a confiança de quem realizou os investimentos. Para isso, eventual comportamento oportunista que busque capturar o benefício proporcionado pelos investimentos de outrem deve ser coibido.

Regras claras e aplicação clara criam previsibilidade e aumentam a harmonia, porque já são um resultado esperado, mas devem sempre ser temperadas com o cuidado de não perseguir cegamente a estabilidade, que tende a reforçar os interesses de quem já detém mais poder e recursos(MACMAHON, 2018, p. 295).

É possível se valer dessa análise da transação tanto para aplicação dos princípios norteadores, como a boa-fé e o dever de informar, até a incidência dos remédios, em caso de descumprimento contratual. De pronto, não parece necessário modificar as regras postas, mas apenas orientar a sua aplicação, como o VAR e seus ângulos múltiplos.

Para exemplificar, menciona-se exemplos de figuras jurídicas há muito conhecidas para a tutela da confiança: (i) vedação ao comportamento contraditório; (ii) surrectio, supressio e tu quoque; e (iii) dever de informar.

Interessante lembrar que o Enunciado no 362 da Jornada de Direito Civil de 2006 afirma que "a vedação do comportamento contraditório (venire contra factumproprium) funda-se na proteção da confiança, tal como se extrai dos arts. 187 e 422 do Código Civil”. Da mesma maneira, o Enunciado no 363 , da mesma Jornada, revela que "os princípios da probidade e da confiança são de ordem pública, estando a parte lesada somente obrigada a demonstrar a existência da violação". A manutenção da confiança constitui, em verdade, um dever jurídico(ROMERO, 2013).

Venire contra factumproprium, por exemplo, impede o comportamento contraditório. A partir dessa prescrição normativa, ninguém está autorizado a contrariar comportamento orientativo praticado por si mesmo. Em situações comerciais, a conduta de um agente pode induzir o comportamento de outro sujeito da relação a tomar determinadas decisões. A mudança de orientação - contrariar atitude própria - significa a quebra da confiança.

Em relações comerciais envolvendo direitos econômicos, contrariar conduta anteriormente tomada importa em mais do que quebra da confiança, mas sim dano jurídico cuja reparação deve ser restabelecida. Além do mencionado artigo $422{ }^{7}$ os artigos $175^{8}, 428^{9}, 476,{ }^{10}$

\footnotetext{
${ }^{7}$ Art. 422. Os contratantes são obrigados a guardar, assim na conclusão do contrato, como em sua execução, os princípios de probidade e boa-fé.

${ }^{8}$ Art. 175. A confirmação expressa, ou a execução voluntária de negócio anulável, nos termos dos arts. 172 a 174 , importa a extinção de todas as ações, ou exceções, de que contra ele dispusesse o devedor.

${ }^{9}$ Art. 428. Deixa de ser obrigatória a proposta:

I - se, feita sem prazo a pessoa presente, não foi imediatamente aceita. Considera-se também presente a pessoa que
} 
$491^{11}$ e $619^{12}$ do Código Civil atual positivam uma repressão ao comportamento contraditório, indicando que o próprio legislador, e não só o mercado, não coaduna com esse comportamento(ROMERO, 2013, p. 65).

Nesse sentido, explica Schreiber que "por trás de qualquer norma em que se possa vislumbrar vedação ao comportamento contraditório, pode-se identificar a tutela da confiança"(2016, p. 93). Adiante, afirma o autor que, "a tutela da confiança atribui ao venire um conteúdo substancial, no sentido de que deixa de se tratar de uma proibição à incoerência por si só, para se tornar um princípio de proibição à ruptura da confiança, por meio da incoerência"(SCHREIBER, 2016, p. 93).

Supressio, surrectio e tu quoque, acima citados,são desdobramentos do princípio do nemopotestvenire contra factumproprium, também destinados à proteção objetiva da confiança criada por um comportamento do agente. O comportamento reiterado, aí entra afrequência como dimensão relevante, gera a expectativa legítima de que se mantenha acontecendo, o que faz com que a relação jurídica se altere.Passa a não ser exigido comportamento diferente das partes, o que pode importar em criação de obrigações ou créditos. Trata-se do direito assumindo que o contrato, em seu curso e não na sua formação, cria direitos e deveres exigíveis juridicamente, a fim de proteger a confiança desenvolvida naquele relacionamento.

O dever de informar, outro exemplo mencionado anteriormente, é outro instituto positivado muito presente nos contratos empresariais. Hillman esclarece que ao formalizar os acordos, o direito contratual promove a transparência e fixa entendimentos que ajudam em conflitos ao longo da relação contratual(HILLMAN, 2007, p. 85-9).O Código Civil assegura por meio dos artigos 518, 569, 613, 686, 769, 856 e 864 figuras específicas da relação jurídica cujo dever de informar decorre de obrigação jurídica: obrigação de assegurar a confiança entre as partes e diminuir os custos de transação.

Analisando as regras existentes no ordenamento, o artigo 473 parágrafo único do Código Civil brasileiro, por exemplo, positiva a tutela da confiança por meio da inclusão da boa-fé na

contrata por telefone ou por meio de comunicação semelhante;

II - se, feita sem prazo a pessoa ausente, tiver decorrido tempo suficiente para chegar a resposta ao conhecimento do proponente;

III - se, feita a pessoa ausente, não tiver sido expedida a resposta dentro do prazo dado;

IV - se, antes dela, ou simultaneamente, chegar ao conhecimento da outra parte a retratação do proponente.

${ }^{10}$ Art. 476. Nos contratos bilaterais, nenhum dos contratantes, antes de cumprida a sua obrigação, pode exigir o implemento da do outro.

${ }^{11}$ Art. 491. Não sendo a venda a crédito, o vendedor não é obrigado a entregar a coisa antes de receber o preço.

12 Art. 619. Salvo estipulação em contrário, o empreiteiro que se incumbir de executar uma obra, segundo plano aceito por quem a encomendou, não terá direito a exigir acréscimo no preço, ainda que sejam introduzidas modificações no projeto, a não ser que estas resultem de instruções escritas do dono da obra. 


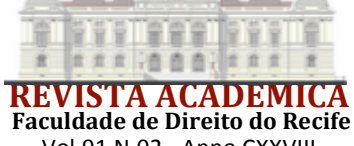

Vol 91 N.02 - Anno C

resilição unilateral. ${ }^{13}$ Impõe que para a produção de efeitos, deve ser levado em conta justamente os investimentos, que podem ser entendidos como ativos específicos pela ECT, e que muitas vezes são irrecuperáveis, os chamados sunkcosts. É uma regra que visa uma finalidade social do dispositivo da resilição do 473 , já que a denúncia contratual, se feita em prazo desarrazoado, pode gerar efeitos econômicos indesejados, que não se limitam ao prejuízo da parte que fez o investimento.

Isto porque, se o comportamento oportunista de encerrar a contratação sem um prazo de retorno do investimento, muitas vezes se apoderando dele, não for afastado, menor será a confiança dos agentes econômicos em realizar aquele tipo de investimento. E como visto, menor a confiança, reduz a realização e aumenta a necessidade de uma atratividade maior, uma possibilidade de lucro muito maior para que motive a realização da transação. Afastar este comportamento oportunista, de encerrar antecipadamente o contrato, está diretamente ligado a incentivar o investimento e aumentar o desenvolvimento, por meio do aumento da confiança.

$\mathrm{Na}$ regra específica, a tutela do que é considerado "prazo compatível” em razão da natureza e vulto dos investimentos demanda análise jurisdicional, na maioria das vezes com fundamento em perícia técnica. Alguns julgados percorrem esse caminho argumentativo sobre a relevância do direito na proteção da confiança encetada nos contratos empresariais, em especial para impedir a quebra da expectativa legitima das partes, que fere o princípio da função social e da boa-fé objetiva, por meio do encerramento imotivado de contratos relacionais e cativos, permeados por um relacionamento que indicava uma maior longevidade da relação. Mesmo tratando-se de partes sofisticadas, com análise específica de riscos (STJ, 2017; TJ/SP, 2012).

É certo quea possibilidade de ser responsabilizado inibe o surgimento de disputas, sendo essa uma maneira do direito funcionar como redutor de conflitos. Porém, é possível também que o direito funcione como canalizador, em situações de conflito, para modos mais pacíficos e eficientes de resolução de disputas. No extremo mínimo, é verdade que a mera perspectiva de um terceiro verificador costuma reduzir a defesa de pontos absurdos, o que pode ser entendido como um redutor de conflito imediato - por meio do distanciamento dos extremos e aproximação de um lugar comum. Convém, no entanto, pontuar que o papel do direito pode não se limitar a isso, sendo possível observar o surgimento de novos caminhos de soluções via cooperação, que também vêm se sustentando em análises econômicas.

\footnotetext{
13 Art. 473. A resilição unilateral, nos casos em que a lei expressa ou implicitamente o permita, opera mediante denúncia notificada à outra parte.

Parágrafo único. Se, porém, dada a natureza do contrato, uma das partes houver feito investimentos consideráveis para a sua execução, a denúncia unilateral só produzirá efeito depois de transcorrido prazo compatível com a natureza e o vulto dos investimentos.
} 
A NEI aponta que estruturas contratuais, como mecanismos para estabelecer a credibilidade dos comprometimentos -a exemplo de garantias e aumento de custo de oportunidade para sair da relação -bem como as técnicas para manter a cooperação com estruturas de governança, podem ser vistas como as bases nas quais as partes alcançam o necessário grau de confiança nas relações contratuais. Isto, juntamente com algumas ideias de design contratual e distribuição de custos ex ante e ex post, fomentam a ideia de um direito contratual procedimental, isto é, focado no procedimento para que as partes, colocadas em um ambiente de resolução, se ajudem, com informações úteis e sugestões para inovação, sem a habitual progressão do conflito.

Parece haver um notório ganho social quando é possível a solução via cooperação, evitando-se o conflito. É possível ao direito atuar como facilitador, o que demanda um profundo estudo da atuação do direito como instrumento de cooperação, mas não parece factível que isto importe na renúncia de sua função tradicional de decidir o conflito.

Mesmo nos casos em que as partes possam se valer de um design contratual extremamente específico para o ambiente de negócios, especialmente os sofisticados ${ }^{14}$, há um limite negocial que esbarra justamente na racionalidade das partes. Talvez uma proposta efetivamente realista e pragmática da realidade contratual brasileira seja um equilíbrio entre regulação prévia - negociação entre as partes - e consequências jurídicas ex post(SHIFFRIN, 2016, p. 407-442). No geral, as partes tendem a se sentir mais seguras com a possibilidade de poder se valer de um adjudicador externo que lhe traga a efetividade do que considera correto dentro dos valores daquela sociedade -, ainda que seja o adjudicador que garanta a ocorrência da solução negocial.

O que se desvela disto tudo é que a forma de atuação do direito, pensado como um todo, como o sistema de coerção que efetivamente produz resultados, deve ser direcionada a tutelar a confiança nos contratos empresariais, por meio de uma mudança hermenêutica na aplicação das regras já existente. Este processo de interpretação dos dispositivos que já servem a tutelar a confiança terá grande desenvolvimento ao se valer das bases da NEI para entender como a sua atuação será compreendida pelo sistema econômico. Entender os efeitos de seus comandos servirá para saber como emanar a ordem para que o resultado dado pelo sistema econômico seja o pretendido pelo sistema jurídico.

\footnotetext{
${ }^{14}$ Neste trabalho, não prosseguimos na digressão sobre a forma de se tutelar contratos em massa em contraponto a forma de se tutelar contratos extremamente sofisticados e trabalhados, mas defendemos a existência e uma diferente abordagem em ambos.
} 


\section{CONCLUSÃO}

O direito, para além da economia, tutela o mundo do conflito, mas também o mundo do planejamento contratual. Como vimos, confiança pode ser algo orgânico no tecido social, mas sua sedimentação depende de elementos jurídicos. A confluência entre oportunismo, racionalidade e assimetria informacional dá as basesda organização contratual, de modo que o direito, tanto como regra imposta top-down como reguladora de um ambiente institucional de confiança, mostra-se como ferramenta importante para a estabilização de expectativas normativas em um ambiente de trocas.

Entende-se que o contrato, por meio dos mecanismos de alocação de riscos e mediação dos interesses, é um instrumento altamente eficaz de minimização dos conflitos, mas que depende de elementos econômicos, sociais e jurídicos para cumprir essa finalidade. $\mathrm{O}$ direito, em especial, parece tutelar a confiança a partir da filtragem dos elementos econômicos e sociais para dentro uma lógica de estabilização da confiança legítima entre partes. Deste modo, embora possa ser usado como instrumento de mitigação do conflito judicial, a regra positivada promove garantias contra o dano jurídico incorrido pela parte.

Aumentar a confiança converge com os valores da sociedade, tanto per si, como pelos efeitos que a sua maximização provoca, o que faz a sua tutela ser algo desejável. Considerando que o direito pode ser usado como ferramenta para expandir a confiança, e tendo em conta que é intenção da sociedade que ela se expanda, até para o alcance de outros valores, como o desenvolvimento, o direito deve ser usado para este fim, tendo a proteção da confiança nos contratos empresariais como um guia, e valendo de sua ação efetiva perante a sociedade, o que não se limita às regras postas, mas envolve a provável resposta dada pelo sistema à situação.

A NEI pode ajudar o direito a alcançar esse fim, por meio de uma compreensão maior da transação e de como os comandos do direito serão compreendidos pelo sistema econômico. O direito não deve virar instrumento da economia, mas saber utilizar o autoconhecimento que a economia tem para que os incentivos criados pelo direito conduzam a economia ao caminho projetado pelos valores protegidos pelo direito.

As regras existentes já proporcionam um bom campo para que a confiança nos contratos empresariais seja protegida e ampliada. A mudança plausível parece ser de interpretação, devendo a proteção da confiança ser considerado um valor protegido pelo direito a orientar a interpretação de todas as regras voltadas a regular os contratos empresariais.

\section{REFERÊNCIAS}


ARAÚJO, Fernando. Teoria económica do contrato. Coimbra: Almedina, 2007.

BERNSTEIN, Lisa. Opting out of the Legal System: Extralegal Contractual Relations in the Diamond Industry. The Journal of Legal Studies, v. 21, n. 1, p. 115-157, jan. 1992.

BRASIL, Superior Tribunal de Justiça (4. Turma). Resp $\mathbf{n}^{\mathbf{0}}$ 1.555.202/SP. Relator: Min. Luis Felipe Salomão, 16 março de 2017.

BRASIL, Tribunal de Justiça de São Paulo.Apelação n ${ }^{\circ}$ 9130138-87.2009.8.26.0000. $6^{\text {a }}$ Câmara de Direito Privado. Des. Francisco Loureiro, 29 de março de 2012.

COASE, Ronald H. The Natureofthefirm.In: WILLIAMSON, Oliver E.; WINTER, Sidney G. (Ed.). The Nature of the Firm: Origins, Evolution and Development. Oxford: Oxford University Press, 1993.

COLLINS, Hugh. Regulating Contracts. Oxford: Oxford University Press, 2004.

COMMONS, John R. Institutional Economics. Madison: University of Wisconsin Press, 1934.

DA FRADA, Carneiro; PORTUGAL, Manuel António de Castro. Teoria da confiança e responsabilidade civil. Coimbra: Almedina, 2007.

FARINA, Elizabeth e Outros. Competitividade: mercado, Estado e organizações . São Paulo: Singular, 1997.

FERRAZ JÚNIOR, Tércio Sampaio. Introdução ao Estudo do Direito. 11. ed. São Paulo: Atlas, 2019.

GIDDENS, Anthony. As consequências da modernidade. São Paulo: Editora Unesp, 1991.

GREENE, Joshua. Moral Tribes: Emotion, reason, and the gap between us and them (English edition). Penguin Books, 2013. Nãopaginado.

HILLMAN, Robert. The richness of contract law: an analysis and critique of contemporary theories of contract law. New York: Springer, 2007.

LLEWELLYN, Karl. What Price Contract? - Na Essay in perspective. Yale Law Journal, v. 40, n. 3, 1931. Disponível em: https://digitalcommons.law.yale.edu/ylj/vol40/iss5/3. Acesso em: 12 jul. 2019.

LUHMANN, Niklas. Confianza. Barcelona: Anthrpos Editorial, 2005.

MACMAHON, Paul. Conflict and Contract Law.Oxford Journal of Legal Studies, v. 38, n. 2, 2018.

MARTINS-COSTA, Judith. Contratos. Conceito e evolução. In: LOTUFO, Renan; NANNI, Giovanni Ettore (coord.). Teoria Geral dos Contratos. São Paulo: Atlas, 2011.

NORTH, Douglas C. Instituições, Mudança Institucional e Desempenho Econômico. 1.ed. Trad. Alexandre Morales. São Paulo: Três estrelas, 2018. 
PEYREFITTE, Alain. A sociedade de confiança. São Paulo: Instituto Piaget, 1997.

REBOUÇAS, Fernandes Rodrigo. Autonomia Privada e a Análise Econômica do Contrato.

São Paulo: Almedina, 2017.p. 160.

ROMERO, Anna Paula Berhnes. A tutela da confiança nos contratos empresariais. Tese (Doutorado em Direito Comercial) - Faculdade de Direito, Universidade de São Paulo, São Paulo, 2013.

SCHREIBER, Anderson. A proibição de comportamento contraditório:tutela de confiança e venire contra factumproprium.São Paulo: Atlas, 2016.

SHIFFRIN, Seana V. Remedial clauses: the overprivatization of private law. Hastings Law Journal, v. 67, p. 407-442.

TEUBNER, Gunther. The Blind Spot: The hybridization of Contracting. TheoreticalInquiries in Law,Frankfurt, $\quad$ v. 7,p. 51-71, 2006. Disponível em: https://papers.ssrn.com/sol3/papers.cfm?abstract_id=893146. Acessoem: 10jul.2019.

WILLIAMSON, Oliver E. The economic institutions of capitalism: firms, markets, relational contracting.New York: The Free Press, 1998.

ZUCKER, L. G. Production of trust: institutional sources of economic structure, 1840-1920.

Research in Organizational Behavior, v. 8, n. 53, 1986. 